\title{
Falência Ovariana Prematura: Aspectos Atuais
}

revisão

\section{LUiz Cesar Vilodre \\ MARCELO MORETTO \\ MARIA BEATRIz DA FONTE KOHEK POLI MARA SPRITZER}

Unidade de Endocrinologia Ginecológica, Serviço de Endocrinologia, Hospital de Clinicas de Porto Alegre (LCV, MM \& PMS); Departamento de Ciências Fisiológicas, FFFCMPA

(MBFK) e Departamento de Fisiologia, ICBS, Universidade Federal do Rio Grande do Sul (PMS), Porto Alegre, RS.

Recebido em 23/10/06 Revisado em 14/03/07 Aceito em 27/06/07

\section{RESUMO}

A falência ovariana prematura (FOP) acomete aproximadamente 1:1000 mulheres antes dos 30 anos, 1:250 em torno dos 35 anos e de 1:100 aos 40 anos. Manifesta-se como amenorréia primária ou amenorréia secundária, não podendo ser considerada definitiva em todas as pacientes, uma vez que a concepção espontânea pode ocorrer em até 5-10\% das FOP. Na maioria dos casos apresenta-se na forma esporádica, pois apenas $5 \%$ apresentam história familial. Entre as causas conhecidas estão as alterações cromossômicas, dos genes ligados ao cromossomo $\mathrm{X}$ e cromossomos autossômicos, doenças autoimunes, alterações tóxicas e iatrogênicas. Com relativa freqüência, a causa etiológica não é obtida, sendo então denominada de idiopática. O diagnóstico da FOP é feito baseado na história clínica e níveis elevados do hormônio folículo estimulante (FSH), sendo posteriormente investigadas as causas mais específicas. O manejo clínico visa o suporte emocional, o tratamento hormonal com estrogênios e progestogênios, a abordagem da infertilidade e a prevenção de co-morbidades como a osteoporose e potencial maior risco cardiovascular. (Arq Bras Endocrinol Metab 2007;51/6:920-929)

Descritores: Falência ovariana prematura; Hipogonadismo hipergonadotrófico; Etrogênio; Terapia hormonal; Infertilidade

\section{ABSTRACT}

Premature Ovarian Failure: Present Aspects.

Premature ovarian failure occurs in approximately 1:1000 women before 30 years, 1:250 by 35 years and 1:100 by the age of 40 . It is characterized by primary or secondary amenorrhea and cannot be considered as definitive because spontaneous conception may occur in 5 to $10 \%$ of cases. In $95 \%$ of cases, premature ovarian failure is sporadic. The known causes of premature ovarian failure include chromosomal defects, autoimmune diseases, exposure to radiation or chemotherapy, surgical procedures, and certain drugs. Frequently, however, the etiology is not clear and these cases are considered to be idiopathic. Premature ovarian failure is defined by gonadal failure and high serum follicle-stimulating hormone (FSH) levels. Clinical approach includes emotional support, hormonal therapy with estrogens and progesterone or progestogens, infertility treatment, and prevention of osteoporosis and potential cardiovascular risk. (Arq Bras Endocrinol Metab 2007;51/6:920-929)

Keywords: Premature ovarian failure; Hypergonadotrophic hypogonadism; Estrogen; Hormonal therapy; Infertility 


\section{DEFINIÇÃO, PREVALÊNCIA E APRESENTAÇÃO CLÍNICA}

\begin{abstract}
A FALÊNCIA OVARIANA PREMATURA (FOP) foi primeiramente definida por Moraes e Jones (1967) como uma condição que leva à amenorréia, infertilidade, hipogonadismo e níveis elevados de gonadotrofinas em mulheres com menos de 40 anos (1). Posteriormente, foram publicados relatos de mulheres com esse diagnóstico que voltavam a menstruar espontaneamente e de casos mais raros em que houve gestação, chamando a atenção para o caráter eventualmente intermitente da evolução clínica $(2,3)$.

A incidência de FOP em pacientes com cariótipo $46 \mathrm{XX}$ gira em torno de 1:1000 antes dos 30 anos, 1:250 em torno dos 35 anos e de 1:100 aos 40 anos. A prevalência de FOP em pacientes com amenorréia primária é de $10-28 \%$ e $4-18 \%$ com amenorréia secundária $(4,5)$. A FOP esporádica é a forma mais comum, porém em cerca de $5 \%$ dos casos observa-se uma história familial positiva, o que sugere uma predisposição genética para essa patologia (6).

A falência ovariana prematura apresenta-se como um quadro de amenorréia e hipogonadismo, em geral precedido em meses ou anos por períodos de irregularidade menstrual. O início preciso da FOP é, em muitos casos, difícil de determinar, pois como já referido, a evolução pode ter um curso flutuante, com níveis elevados de gonadotrofinas seguidos por períodos de retorno à normalidade, inclusive com ovulação e, em 5 a $10 \%$ dos casos, gestação e parto $(5,7)$. Essa variabilidade da evolução clínica foi também observada numa coorte de 39 pacientes com FOP e cariótipo 46 $\mathrm{XX}$, que estão sendo acompanhadas na Unidade de Endocrinologia Ginecológica do Serviço de Endocrinologia, no Hospital de Clínicas de Porto Alegre. Verificou-se nestas pacientes que a idade mediana da última menstruação variou de 14 a 39 anos, e que a duração da irregularidade menstrual antes do diagnóstico firmado de FOP foi inferior a 3 anos em $44 \%$ da amostra e superior a 9 anos em 16\% das pacientes (8).
\end{abstract}

\section{ETIOLOGIA E CLASSIFICAÇÃO DA FOP}

As causas da falência ovariana prematura são múltiplas e resultam em redução no número de folículos e/ou defeitos nos mecanismos de estímulo ao desenvolvimento folicular. Por outro lado, embora a divisão em pacientes com e sem folículos presentes seja utilizada, alguns casos de FOP que inicialmente eram do tipo folicular podem evoluir para um estágio afolicular. Do ponto de vista etiológico, a FOP pode ser classificada em duas categorias: depleção folicular e disfunção folicular (quadro).

\section{Depleção folicular}

Pode ocorrer por uma deficiência folicular primordial ou por uma aceleração na atresia folicular. Com relação aos casos de deficiência no número de folículos, a maioria das pacientes apresenta cariótipo normal e não está(ão) ainda estabelecido(s) o(s) mecanismo(s) que explique $(\mathrm{m})$ a apoptose oocitária com conseqüente diminuição dos oócitos ovarianos ao nascimento. Por isso, são classificados como FOP idiopática e representam grande parte dos casos de falência ovariana espontânea.

A atresia folicular acelerada está associada a causas genéticas, doenças autoimunes, causas iatrogênicas e associadas a toxinas e agentes virais.

\section{Causas genéticas}

\section{Alterações genéticas relacionadas ao cromossomo $X$}

$\mathrm{O}$ desenvolvimento da gônada indiferenciada em ovário dá-se na ausência do cromossomo Y. A diferenciação ovariana necessita da presença de apenas um X, embora seja imprescindível a presença dos genes do segundo X para a manutenção da função ovariana (9). Assim, a associação da FOP com alterações relacionadas ao cromossomo X reforça a hipótese da necessidade de dois X intactos para o desenvolvimento normal do folículo.

A monossomia do cromossomo $\mathrm{X}$, conhecida como síndrome de Turner, é a mais freqüentemente diagnosticada, com uma incidência de 1:2500 nascidos vivos do sexo feminino. Geneticamente, $57 \%$ apresentam cariótipo $45 \mathrm{X}$, sendo os $43 \%$ restantes representados por deleções completas do braço curto do X, resultando em isocromossomia para o braço longo do $\mathrm{X},[46, \mathrm{Xi}(\mathrm{Xq})]$ e deleção parcial do braço curto do X [46,X $(\mathrm{Xp})]$. O mosaicismo mais freqüente é $46 \mathrm{XX} / 45 \mathrm{X}$ sendo que em $80 \%$ dos casos o X perdido é de origem paterna (10).

Embora as trissomias do X afetem 1:900 mulheres na população geral, a primeira associação com FOP foi descrita em 1959 por Jacobs e cols., referido em Goswami e cols. (2003), sendo relatadas como formas esporádicas de comprometimento (11). As deleções comprometem mais comumente o braço curto do cromossomo $\mathrm{X}$, em especial a região Xq13-25, levando à perda de pareamento e atresia dos oócitos (9).

Por outro lado, a região de maior importância para o funcionamento ovariano normal tem sido considerada a Xq13-q26 (12), sendo que translocações nesta região levam à apoptose oocitária com perda da 
Quadro. Classificação etiológica da Falência Ovariana Prematura.

\begin{tabular}{|c|c|}
\hline DEPLEÇÃO FOLICULAR & \\
\hline Número folicular inicial o & deficiente \\
\hline Idiopática & \\
\hline Atresia folicular acelerad & \\
\hline CAUSAS GENÉTIC & \\
\hline Anormalic & dades do cromossomo $X$ \\
\hline & Síndrome de Turner \\
\hline & X Frágil \\
\hline Doenças a & autossômicas \\
\hline & Blepharophimosis \\
\hline & Galactosaemia \\
\hline & APECD* \\
\hline & CDG1* \\
\hline Relaciona & da a genes de hormônios/ receptores hormonais \\
\hline & FSHR* \\
\hline & $\mathrm{LHR}^{*}$ \\
\hline & INIBINA \\
\hline ASSOCIADA A DOE & ENÇAS AUTOIMUNES \\
\hline & Doença de Addison \\
\hline & Miastenia gravis \\
\hline & Tireoidite de Hashimoto \\
\hline & Vitiligo \\
\hline & Artrite reumatóide \\
\hline & LES* \\
\hline CAUSAS IATROGÊI & NICAS \\
\hline & Cirurgia/ irradiação pélvica \\
\hline & Quimioterapia \\
\hline ASSOCIADA A TOX & XINAS E AGENTES VIRAIS \\
\hline DISFUNÇÃO FOLICULAR & \\
\hline Idiopática & \\
\hline DEFICIÊNCIA ENZIN & MÁTICA \\
\hline & 17- $\alpha$-Hidroxilase \\
\hline & 17-20 Desmolase \\
\hline & Colesterol-desmolase \\
\hline
\end{tabular}

* APECD: Poliendocrinopatia autoimune-candidíase-distrofia ectodérmica, CDG1: glicoproteína carboidrato tipo 1, FSHR: receptor do FSH, LHR: receptor do LH, LES: Lupus eritematoso sistêmico.

Modificado de Anasti e cols., 1998, e Laml e cols., 2002.

função ovariana. Porém, dois segmentos fora desta região são definidos como contendo o locus para a falência ovariana: FOPI (Falência ovariana prematura 1), que compreende Xq26-qter, e FOP2 (Falência ovariana prematura 2), Xq13.3-Xq22. Evidências sugerem que translocações distais que afetem o segmento cromossômico $F O P I$ resultam em falência ovariana entre 24 e 29 anos, enquanto que mutações em FOP2 causam disfunção ovariana mais precocemente, entre 16 e 21 anos (13).

A síndrome do X Frágil (FRAXA) é causada pela expansão das repetições CGC na região 5 ' não traduzida (UTR) do gene FMRI no braço longo do cromossomo X (Xq27.3). O número de repetições CGC é altamente variável na população normal, mas considera-se como pré-mutação entre 60 e 200 repetições porque alelos pré-mutados são suscetíveis de expansão quando passam de uma geração a outra. A mutação é definida pelo número de repetições CGC superior a 200, causando hipermetilação da região promotora do gene FMRI e conseqüentemente o silenciamento de sua transcrição. Este resulta no fenótipo de retardo mental mais freqüente nos homens. Estudos têm demonstrado que na FOP familial a incidência desta pré-mutação está em torno de $13 \%$, enquanto na FOP esporádica, em apenas 3\% (14), 
sendo que em $28 \%$ das FOP a herança é paterna e em 4\%, materna (15). Assim, a investigação genética na FOP familial para a pré-mutação do gene FMRI está indicada, visando o aconselhamento genético das famílias. Neste sentido, a identificação de uma paciente como carreadora de premutação para FRAXA deve levar ao rastreamento de irmãs e primas que são ainda férteis, além de excluir eventual familiar afetada como potencial doadora de oócitos.

Mais recentemente, foi identificada em oócitos a expressão da proteína morfogenética do osso (BMPl5), que é responsável pela produção de fatores de crescimento e diferenciação e está envolvida com a foliculogênese e o crescimento das células da granulosa (16). O gene da BMP15 está localizado no Xpl1.2, uma região que foi descrita recentemente como crítica para a manutenção da função ovariana, uma vez que deleções de Xp11.2-11.4 são acompanhadas de amenorréia primária, secundária ou infertilidade, sendo que uma mutação neste gene pode levar à ausência de resposta oocitária e conseqüente falência do mesmo (17).

\section{Alterações relacionadas a genes autossômicos}

Alterações relacionadas a genes autossômicos estão presentes também em alguns casos de FOP. A síndrome blefarofimose-ptose-epicanto inversa (BPES) é uma doença autossômica dominante causada por mutações no gene do fator de transcrição FOXL2 e caracteriza-se pela presença de malformação das pálpebras, entre outras alterações faciais, muitas vezes associadas à FOP. O mapeamento de casos familiais levou à identificação de um locus no braço longo do cromossomo 3 (3q23) e, posteriormente, foram identificadas mutações pontuais no gene FOXL2. A BPES manifesta-se de duas formas: tipo I e tipo II, sendo que apenas o primeiro tipo está associado à FOP. Esta variabilidade é decorrente do tipo de mutação presente no gene FOXL2, que produz proteína truncada devido a uma mutação sem sentido (18).

A galactosemia é um erro inato do metabolismo, devido a uma alteração autossômica recessiva e que se caracteriza por uma incapacidade em converter galactose em glicose decorrente de uma deficiência das enzimas: Galactoquinase, Galactose-1-P-Uridil transferase e Uridina-Difosfogalactose epimerase. O acúmulo de metabólitos da galactose (galactitol e galactonato) compromete vários órgãos, entre eles os ovários, levando à diminuição do número de oogônias com dano folicular e resultando em FOP, numa freqüência de até 60-70\% dos casos (19). Os três genes GALT responsáveis por estas alterações enzimáticas estão localizados respectivamente: $G A L T-9 p 13$, GALK-17q24 e GALE-1p36 (20).

A síndrome caracterizada por poliendocrinopatia autoimune-candidíase-distrofia ectodérmica (APECED) é uma doença autossômica recessiva rara que se manifesta pela destruição dos tecidos endócrinos imuno-dependentes, sendo seu diagnóstico firmado quando duas das seguintes manifestações clínicas estão presentes: candidíase, hipoparatireoidismo e insuficiência adrenal primária (21). O gene AIRE está localizado no cromossomo $21 \mathrm{lq} 22.3$ e observa-se associação com FOP em aproximadamente $60 \%$ dos casos com mutação neste gene (22).

A síndrome da deficiência da glicoproteína carboidrato tipo l (CDGl) é uma doença autossômica recessiva rara. Caracteriza-se por alterações na glicosilação causadas pela deficiência da enzima fosfomanomutase (PMM), levando a alterações neurológicas importantes com letalidade de até $20 \%$ no primeiro ano de vida. O gene PMMI está localizado no cromossomo 22q13 e o PMM2, no cromossoma $16 \mathrm{pl3}$. Mutações no gene PMM2 foram já identificadas em pacientes com FOP (23).

Embora inúmeras mutações ativadoras e inativadoras tenham sido identificadas no gene do receptor do LH (LHR), apenas oito mutações inativadoras de herança recessiva foram identificadas no gene do receptor do FSH (FSHR) até o presente. Em 1995, Aittomaki e cols. estudaram 75 casos de disgenesia ovariana com cariótipo normal e FSH elevado em uma população da Finlândia composta por seis famílias onde pelo menos dois membros eram afetados, o que, através da análise de ligação genética, possibilitou o mapeamento do locus do cromossomo 2 (24). O gene do FSH localiza-se no locus 21 do braço curto do cromossomo 2, 2p21-pl6 (25). A primeira mutação foi descrita em 1996, por Aittomaki e cols. (26), que estudaram 22 mulheres finlandesas com amenorréia primária, $46 \mathrm{XX}$, com padrão de herança recessivo (tabela 1). Todas apresentaram uma mutação em ponto, citosina $(\mathrm{C})$ para timina $(\mathrm{T})$, na posição 566 do exon 7 do gene do FSHR. Essa mutação leva à substituição da alanina pela valina no resíduo 189 da proteína do FSHR, mudando, assim, sua estrutura. A descrição desta mutação no gene do FSHR contribuiu para o entendimento da endocrinologia ovariana e caracterização fenotípica dessas pacientes (26).

Mais recentemente, sete outras novas mutações foram identificadas (tabela 1). Estas mutações estão localizadas nos exons 6, 7, 9 e 10 do gene do FSHR e todas levam à substituição de aminoácidos na proteína, alterando a conformação protéica e/ou interferindo 
Tabela 1. Mutações e polimorfismos descritos no gene do receptor do FSH.

\begin{tabular}{|c|c|c|c|}
\hline Autores & Exon & Mutação & Polimorfismo \\
\hline Aittomaki e cols., 1996 (26) & 7 & Ala $189 \mathrm{Val}$ & \\
\hline Beau e cols., 1998 (27) & $6-10$ & $\begin{array}{c}\text { Ile } 160 \mathrm{Thr} \\
\text { Arg } 573 \text { Cys }\end{array}$ & \\
\hline Da Fonte Kohek e cols., 1998 (32) & $7-10$ & & $\begin{array}{l}\text { Ala } 307 \text { Thr } \\
\text { Ser } 680 \text { Ans }\end{array}$ \\
\hline Touraine e cols., 1999 (28) & $9-10$ & $\begin{array}{l}\text { Asp } 224 \mathrm{Val} \\
\text { Leu } 601 \mathrm{Val}\end{array}$ & \\
\hline Doherty e cols., 2002 (29) & $7-10$ & $\begin{array}{l}\text { Ala } 189 \mathrm{Val} \\
\text { Ala } 419 \mathrm{Thr}\end{array}$ & \\
\hline Allen e cols., $2003(30)$ & 10 & Pro348 Arg & \\
\hline Meduri e cols., 2003 (31) & 10 & Pro 519 Thr & \\
\hline Sundblat e cols., 2004 (33) & $1-10$ & & $\begin{array}{l}\text { Ala } 307 \text { Thr } \\
\text { Ser } 680 \text { Ans }\end{array}$ \\
\hline
\end{tabular}

no trajeto do receptor à superfície celular (27-31). A amenorréia primária estava presente na maior parte das pacientes com as mutações relatadas (Asp224Val/ Leu601Val, Ala189Val/Ala419Thr e Pro519Thr) (28-31), enquanto que a amenorréia secundária foi identificada apenas na paciente portadora da mutação Ile160Thr/Arg573Cys (27). No Brasil, da Fonte Kohek e cols. (1998) avaliaram vinte e cinco mulheres com amenorréia primária e diagnóstico de falência ovariana prematura e, embora não tenham encontrado as mutações descritas por Aittomaki e cols., identificaram a presença de dois polimorfismos no gene do FSHR: Ala307Thr e Ser680Ans (32). Em 2004, Sundblad e cols. descreveram os resultados do rastreamento do gene do FSHR em mulheres argentinas com FOP, não tendo encontrado nenhuma com mutação, porém vinte delas apresentavam os polimorfismos Ala307Thr e Ser680Ans (33).

O gene do LHR, localizado no braço curto do cromossomo 2, locus 21, foi associado com FOP por Latronico e cols., em uma mulher com amenorréia e resistência ovariana ao $\mathrm{LH}$, em decorrência de uma substituição em homozigose de uma timina por uma citosina na posição 1660 do gene do LHR (34).

A inibina, uma glicoproteína produzida nas células da granulosa, tem como principal função o controle sobre o FSH, e, assim, um papel importante no recrutamento e desenvolvimento folicular. Mac-Naughton e cols. (1992) demonstraram uma relação direta entre a perda da reserva folicular com a diminuição da concentração sérica da inibina (35). Os genes da inibina alfa (INHA), inibina beta $\mathrm{A}(I N H B A)$ e inibina beta $\mathrm{B}(I N H B B)$ codificam esta glicoproteína, sendo que muitos estudos têm confirmado a relação entre esses genes e a fisiopatologia da FOP (36).

\section{Associação com doenças autoimunes}

A associação da FOP com doenças autoimunes é bem conhecida e pode atingir até $30 \%$ dos casos (37). As doenças autoimunes da tireóide estão presentes em até $20 \%$ dos casos de FOP, sendo que outras alterações tais como hipoparatireoidismo, diabetes mellitus e hipofisite também são relatadas (7). Associações com doenças autoimunes não endócrinas, como púrpura trombocitopênica idiopática, vitiligo, alopecia, anemia perniciosa, lupus eritematoso sistêmico, síndrome de Sjogren, hepatite crônica ativa, anemia autoimune hemolítica, doença de Crohn e artrite reumatóide, também são conhecidas (2l). Entretanto, a presença de ooforite ao exame histológico encontra-se praticamente restrita aos casos de doença de Addison, ocorrendo em menos de $3 \%$ na ausência desta patologia (21).

A ooforite autoimune é caracterizada por infiltração linfocítica e células plasmáticas ao nível das células hilares, teca interna dos folículos em crescimento e corpo lúteo. Na maioria dos casos, existe uma falta de folículos ovarianos e algumas vezes as glândulas parecem fibróticas, ou seja, em fita (38).

Os autoanticorpos para células esteróides são muito raros em soro de paciente com falência ovariana sem doença de Addison. Embora haja evidências para a doença autoimune do ovário, a falta de um marcador específico para diagnosticar autoanticorpos ocorre devido aos diferentes tipos celulares que podem estar envolvidos, como as células do corpo lúteo, da zona pelúcida, do receptor do FSH e o próprio oócito. Muitos autoanticorpos para as gônadas têm sido detectados pelo método de Elisa em pacientes com FOP isolada ou associada com doenças autoimunes não-Addison, porém sua especificidade e papel patogênico são questionáveis (39). 


\section{Causas iatrogênicas e associadas a toxinas e agentes virais}

Entre as causas iatrogênicas, a radioterapia, a quimioterapia e as cirurgias pélvicas são as mais comuns. Os efeitos adversos da radiação ionizante sobre a função gonadal dependem da dose, área de irradiação e idade, pois os ovários na pré-puberdade apresentam maior grau de resistência a este tipo de toxicidade. As diversas classes de quimioterápicos, freqüentemente utilizadas de forma associada, também comprometem as gônadas, principalmente a estrutura e a função das células da granulosa e oócitos, sendo este efeito droga, dose e idade dependente (6). As cirurgias pélvicas também podem levar à FOP a partir do comprometimento do suprimento sanguíneo ou como seqüela de processos inflamatórios. Mais recentemente, a embolização da artéria uterina para o tratamento dos leiomiomas tem sido associada à diminuição da fertilidade e complicações durante a gestação, assim como à diminuição da função ovariana e FOP em até 14\% (40).

O fumo, através do hidrocarbono policíclico aromático encontrado no cigarro, causa a destruição dos oócitos, levando à falência ovariana permanente em experimentos em animais de laboratório (4l). Embora mulheres fumantes apresentem a menopausa mais cedo em relação às não fumantes, ainda faltam estudos que comprovem que essa condição se dá pelo efeito do cigarro (42). Em relação ao comprometimento ovariano como conseqüência de viroses, toxinas, metais pesados e produtos químicos, ainda faltam estudos em humanos que sejam suficientemente esclarecedores.

\section{Disfunção ovariana folicular}

Algumas pacientes com FOP podem apresentar folículos de aparência normal que, embora sejam submetidos a concentrações circulantes adequadas de gonadotrofinas, falham na indução da síntese de estrogênios, resultando em amenorréia hipergonadotrófica. Embora muitas dessas pacientes apresentem uma disfunção ovariana folicular idiopática, também denominada síndrome dos ovários resistentes, algumas causas específicas e raras devem ser consideradas, entre elas a deficiência em enzimas relacionadas com a síntese de estradiol. A redução na estrogenemia por deficiência enzimática causa retardo puberal, amenorréia primária e níveis aumentados de gonadotrofinas, apesar da presença de folículos primordiais no ovário $(5,7)$. Enzimas cujas deficiências estão envolvidas com redução na síntese ovariana de estradiol são a colesterol-desmolase, 17-20 desmolase e 17- $\alpha$ hidroxilase.

\section{DIAGNÓSTICO}

O diagnóstico de FOP é baseado na história clínica e pela demonstração de níveis elevados de gonadotrofinas. Entretanto, freqüentemente o diagnóstico é retardado pela demora na avaliação diagnóstica destas pacientes. As pacientes com FOP e amenorréia secundária apresentam, em geral, menarca na idade habitual, ciclos inicialmente regulares e que, a partir de um determinado período, tornam-se irregulares variando de oligomenorréia a períodos de amenorréia, até a cessação completa das menstruações $(7,8)$. Inicialmente, e dependendo do grau de comprometimento ovariano, podem ser mais evidentes os sintomas vasomotores, como fogachos e sudorese, alteração de humor e insônia, evoluindo mais tardiamente para a atrofia do trato urogenital, com maior propensão para vaginites, cistites e dispareunia.

Assim, uma vez afastada a gestação, serão inicialmente solicitadas dosagens de $\mathrm{FSH}$, prolactina e hormônio estimulante da tireóide (TSH). Níveis séricos de FSH maiores do que $40 \mathrm{UI} / \mathrm{L}$, repetidos pelo menos duas a três vezes, com intervalo superior a 1 mês, são fundamentais para o diagnóstico, embora não reflitam a perda total da função ovariana. Nelson e cols. (1992) demonstraram que $50 \%$ das mulheres com esse diagnóstico apresentavam função folicular ovariana quando definido pelos níveis séricos de estradiol maiores do que $50 \mathrm{pg} / \mathrm{ml}$, e aproximadamente $20 \%$ delas ovulavam, se considerados níveis de progesterona iguais ou superiores a $3 \mathrm{ng} / \mathrm{ml}(7)$.

Uma vez feito o diagnóstico, exames mais específicos serão solicitados, dependendo de cada caso, para tentar elucidar a etiologia, incluindo a pesquisa de doenças autoimunes. A dosagem do estradiol pode ser realizada para confirmar o hipogonadismo, sendo dispensável diante de sintomas vasomotores ou outros sinais de deficiência estrogênica.

A ultra-sonografia pélvica, ou preferencialmente transvaginal, pode identificar a presença e determinar o volume de folículos ovarianos. Cerca de $25 \%$ a $40 \%$ de pacientes com FOP apresentam folículos ovarianos à ultra-sonografia pélvica (43). Por outro lado, o papel da biópsia ovariana, no diagnóstico e prognóstico da FOP, é controverso e há relatos de gestações ocorridas em pacientes com biópsia negativa (22). A biópsia ovariana com ausência de folículo pode refletir apenas uma amostra inadequada de tecido, assim como a presença deles não implicar numa resposta positiva ao tratamento (44).

Quanto à análise citogenética, no passado somente as pacientes com FOP em amenorréia pri- 
mária ou em amenorréia secundária com idade inferior a 30 anos eram consideradas para realizar o cariótipo. Entretanto, com estudos posteriores demonstrando a presença de anormalidades cromossômicas em mulheres que iniciaram a FOP com idade superior a 30 anos, a realização do cariótipo tem sido sugerida em todas as mulheres com FOP (22). A falência ovariana prematura com amenorréia primária está associada à alteração de cariótipo em aproximadamente 50\% dos casos, porém as pacientes com FOP apresentam, com freqüência, amenorréia secundária.

Embora muitos casos de FOP sejam idiopáticos, as causas conhecidas e fatores genéticos estão aumentando rapidamente com o avanço dos estudos na área. No momento atual, as causas genéticas são muito raras e o rastreamento genético para todos os casos não está indicado, exceto em centros de pesquisa. Contudo, situações mais comuns e que podem ter outras conseqüências, como síndrome de Turner, carreadoras da premutação do gene FMRI (FRAXA) e autoimunidade devem ser investigadas.

\section{TRATAMENTO}

O manejo clínico da paciente com FOP é abrangente e envolve o suporte emocional desde o momento do diagnóstico, a abordagem da infertilidade, o tratamento hormonal e a prevenção/tratamento de doenças associadas (autoimunes) ou decorrentes do próprio hipoestrogenismo.

\section{Terapia de reposição hormonal}

Ao contrário do tratamento hormonal da mulher climatérica, na FOP ainda não estão disponíveis estudos a longo prazo que avaliem os riscos desta terapia, como eventos cardiovasculares e câncer de mama, o que não autoriza a utilização de estudos como o Women's Health Initiative (WHI) para basear o tratamento destas mulheres. De fato, a TRH para as mulheres jovens deve ser encarada como a necessidade de substituição de hormônios ovarianos numa situação de evidente hipogonadismo e suas conseqüências a curto e longo prazo. Este conceito também fundamenta o tempo de uso da terapia hormonal, que deve ser continuada até os 50 anos, idade média da menopausa, quando então será reavaliada (7). Além disso, a ausência de estudos controlados a longo prazo que comparem segurança e eficácia para o estrogênio, a progesterona/progestogênio e o regime (cíclico ou contínuo) ideal, faz com que a abordagem terapêutica da FOP seja necessariamente individualizada.
Os estrogênios podem ser utilizados por via oral, transdérmica, subcutânea e vaginal. A via oral é a mais utilizada, possivelmente por ter menor custo e ser utilizada há mais tempo, sendo que o alívio dos sintomas vasomotores assim como os efeitos adversos do estradiol 17- $\beta$ (E2) e dos estrogênios eqüinos conjugados (EEC) são muito semelhantes. A via transdérmica, gel ou patch (adesivo), tem-se mostrado uma excelente opção por ser de fácil aplicação, rapidamente absorvida e metabolizada e ter a vantagem de evitar a primeira passagem hepática $(45,46)$. A dose do estrogênio a ser prescrita deve alcançar níveis séricos de estradiol correspondentes ao de um ciclo menstrual normal, ou seja, próximo de 104 pg/ml, o que na prática clínica corresponde a doses maiores do que aquelas normalmente utilizadas para o alívio dos sintomas vasomotores nas mulheres na pós-menopausa (47). Assim, doses de $2 \mathrm{mg}$ de estradiol micronizado (E2), 0,9-1,25 mg de EEC ou $100 \mu \mathrm{g}$ de estradiol transdérmico podem ser necessárias. A via subcutânea necessita inserção no abdome, braço ou glúteos do pellet de 25-50 mg de estradiol, o qual fará a liberação lenta do mesmo em aproximadamente 6 meses (47). A via vaginal oferece uma absorção predominantemente local, a partir de cremes e pessários medicados e é certamente a menos utilizada, ficando restrita a casos específicos.

A progesterona e os progestogênios são utilizados na TRH de pacientes com FOP e presença de útero para contrapor o efeito mitogênico do estrogênio sobre o endométrio, evitando assim a hiperplasia endometrial. Estão disponíveis para uso por via oral, vaginal, intramuscular e transdérmico, estando suas ações e efeitos adversos relacionados com as diferenças em seu metabolismo. Os níveis circulantes dependem, portanto, da absorção, metabolismo no trato gastrointestinal (primeira passagem hepática), armazenamento no tecido adiposo e outros tecidos e sua ligação com as proteínas séricas.

Assim, as doses necessárias de progesterona e progestogênios dependerão do regime hormonal a ser ministrado, ou seja, se cíclico (10-14 dias ao mês) ou contínuo e do tipo de hormônio disponível. A progesterona micronizada pode ser usada no esquema seqüencial na dose de $200 \mathrm{mg} /$ dia durante 10-12 dias e $100 \mathrm{mg} /$ dia no esquema contínuo. O acetato de medroxiprogesterona, $10 \mathrm{mg} /$ dia durante 10-12 dias no seqüencial, enquanto $2,5 \mathrm{mg} /$ dia no contínuo. $\mathrm{O}$ acetato de ciproterona, na dose de $1 \mathrm{mg} /$ dia, está disponível em nosso meio em associação com valerato de estradiol $2 \mathrm{mg}$, para regime seqüencial. Entretanto, essa associação tem a desvantagem de deixar uma 
janela de uma semana sem tratamento. A noretisterona $1 \mathrm{mg} /$ dia durante 10-12 dias deve ser utilizada no esquema seqüencial e $0,5 \mathrm{mg} /$ dia no contínuo (48).

A escolha do regime hormonal a ser usado dependerá do desejo da paciente em menstruar ou não. Porém, os estrogênios utilizados para o tratamento da FOP não suprimem a ovulação mesmo em regimes contínuos e conseqüentemente não impedem a concepção, uma vez que nem sempre normalizam os níveis de gonadotrofinas. Assim, é preferível optar-se por esquemas cíclicos, pois diante de um atraso menstrual deve-se suspender a TRH imediatamente até excluir uma gestação.

Quanto aos androgênios, não existem estudos suficientes que justifiquem a reposição de rotina. Embora tenham sido descritos níveis circulantes de androgênios inferiores em mulheres jovens com FOP em comparação com mulheres normais, os valores foram limítrofes ou discretamente abaixo dos limites inferiores da normalidade, e o significado clínico deste dado não está ainda bem definido $(49,50)$.

Algumas pacientes preferem utilizar o anticoncepcional oral como tratamento, por considerar seu uso mais prático. Entretanto, deve-se levar em conta que as doses de estrogênio e progestogênios contidos nessas apresentações são fixas, estão além do necessário para uma reposição fisiológica e, na maioria das apresentações, deixam uma janela de uma semana sem estrogênios, o que é inadequado nestas pacientes $(6,7)$.

\section{Infertilidade}

Apenas cerca de $5-10 \%$ das mulheres com FOP engravidam espontaneamente ou durante o tratamento. Porém, essas gestações ocorrem quase que exclusivamente em mulheres que apresentaram amenorréia secundária, sendo que em pacientes com amenorréia primária a prevalência de gestação é quase nula (6). Essas gestações ocorreriam em conseqüência da flutuação dos níveis hormonais ou atividade da doença básica, fazendo com que as células da granulosa se tornassem sensíveis ao FSH com conseqüente crescimento folicular e ovulação, mesmo em mulheres em uso de contraceptivo oral (51).

Tendo em vista as evidências de ineficácia do uso do citrato de clomifeno isolado ou associado a gonadotrofinas ou $\mathrm{FSH}$ recombinante em pacientes com FOP (51), a opção terapêutica para infertilidade nestas pacientes é a fertilização in vitro (FIV) com óvulo de doadora, cujas taxas de gestação chegam a $50 \%$ por ciclo $(5,52)$.

Recentemente Donnez e cols. (2004) publicaram o primeiro nascimento, fruto de transplante de tecido ovariano crioprecipitado. Esta técnica representa, portanto, uma alternativa promissora para mulheres que serão submetidas a tratamento com quimioterápicos ou radioterapia em região pélvica (53).

\section{Prevenção de osteoporose e doença cardiovascular}

As pacientes com FOP representam uma população com maior risco potencial para o desenvolvimento de osteoporose e fraturas futuras, sendo justificável o uso de medidas preventivas e terapêuticas. Apesar de não haver estudos prospectivos que avaliem o impacto do estrogênio sobre fraturas especificamente em mulheres com FOP, evidências sugerem que a TRH aumenta a densidade mineral óssea independente da dose, via de administração ou regime terapêutico.

Além da TRH, medidas de prevenção devem ser associadas e consistem em atividade física diária com peso, dieta alimentar adequada em cálcio e vitamina $\mathrm{D}$, assim como evitar condições que promovam a perda óssea como o tabagismo e abuso de bebidas alcoólicas. Em situações específicas, a prescrição de cálcio assim como vitamina D está indicada (54).

Estudos epidemiológicos sugerem que mulheres com FOP apresentam maior risco para mortalidade de causa cardiovascular. Kalantaridou e cols. (2006) demonstraram que mulheres com FOP, quando comparadas com controles com função ovariana normal, apresentam uma disfunção endotelial significante, sugerindo que a aterosclerose inicia precocemente nestas mulheres (55). Porém, essa alteração pode ser reversível com seis meses de terapia hormonal cíclica. Estudos futuros são necessários para esclarecer se esta recuperação endotelial significa redução dos eventos cardiovasculares ou não (55).

A falência ovariana prematura é uma condição clínica complexa que ocorre em mulheres jovens e que pode ter inúmeras causas. Entretanto, não pode ser confundida com a menopausa normal, uma vez que pode ter uma evolução intermitente, com retorno mesmo que temporário aos ciclos menstruais normais e inclusive com possibilidade de gestação. Independentemente da etiologia, essas pacientes devem receber terapia de reposição hormonal com estrogênios e progestogênios, favorecendo assim a manutenção do trofismo dos tecidos do trato reprodutivo, os ciclos menstruais e a prevenção da perda de massa óssea.

\section{REFERÊNCIAS}

1. Moraes-Ruehsen M, Jones GS. Premature ovarian failure. Fertil Steril 1967;18(4):440-61. 
2. Johnson TR Jr, Peterson EP. Gonadotropin-induced pregnancy following "premature ovarian failure". Fertil Steril 1979;31(3):351-2.

3. Lucky AW, Rebar RW, Blizzard RM, Goren EM. Pubertal progression in the presence of elevated serum gonadotropins in girls with multiple endocrine deficiencies. J Clin Endocrinol Metab 1977;45(4):673-8.

4. Anasti JN. Premature ovarian failure: an update. Fertil Steril 1998;70(1):1-15.

5. Van Kasteren YM, Schoemaker J. Premature ovarian failure: a systematic review on therapeutic interventions to restore ovarian function and achieve pregnancy. Hum Reprod Update 1999:5:483-92.

6. Goswami D, Conway GS. Premature ovarian failure. Hum Reprod Update 2005;11(4):391-410.

7. Nelson LM, Covington SN, Rebar RW. An update: spontaneous premature ovarian failure is not an early menopause. Fertil Steril 2005;83(5):1327-32.

8. Vilodre LC, Kohek MBF, Spritzer PM. Screening of FSH receptor gene in women with premature ovarian failure (POF) in southern Brazil and associations with phenotype. P1-337, Annals of the 89th Endo Soc Meeting, Toronto, Canada, June 2-5, 2007.

9. Simpson JL, Rajkovic A. Ovarian differentiation and gonadal failure. Am J Med Genet 1999;89(4):186-200.

10. Loughlin SA, Redha A, Mclver J, Boyd E, Carothers A, Connor JM. Analysis of the origin of Turner's syndrome using polymorphic DNA probes. J Med Genet 1991;28(3):156-8.

11. Goswami R, Goswami D, Kabra M, Gupta N, Dubey S, Dadhwal V. Prevalence of the triple $\mathrm{X}$ syndrome in phenotypically normal women with premature ovarian failure and its association with autoimmune thyroid disorders. Fertil Steril 2003;80(4):1052-4.

12. Therman E, Laxova R, Susman B. The critical region on the human Xq. Hum Genet 1990:85(5):455-61.

13. Powell CM, Taggart RT, Drumheller TC, Wangsa D, Qian C, Nelson LM, et al. Molecular and cytogenetic studies of an $\mathrm{X}$;autosome translocation in a patient with premature ovarian failure and review of the literature. Am J Med Genet 1994;52(1):19-26

14. Conway GS, Payne NN, Webb J, Murray A, Jacobs PA. Fragile $X$ premutation screening in women with premature ovarian failure. Hum Reprod 1998;13(5):1184-7.

15. Hundscheid RD, Sistermans EA, Thomas CM, Braat DD, Straatman $\mathrm{H}$, Kiemeney LA. Imprinting effect in premature ovarian failure confined to paternally inherited fragile $X$ premutations. Am J Hum Genet 2000;66(2):413-8.

16. Dube JL, Wang P, Elvin J, Lyons KM, Celeste AJ, Matzuk MM. The bone morphogenetic protein 15 gene is X-linked and expressed in oocytes. Mol Endocrinol 1998;12(12):1809-17.

17. Di Pasquale E, Rossetti R, Marozzi A, Bodega B, Borgato S, Cavallo $L$, et al. Identification of new variants of human BMP15 gene in a large cohort of women with premature ovarian failure. J Clin Endocrinol Metab 2006;91(5):1976-9.

18. Oley C, Baraitser M. Blepharophimosis, ptosis, epicanthus inversus syndrome (BPES syndrome). J Med Genet 1988;25(1):47-51

19. Waggoner DD, Buist NR, Donnell GN. Long-term prognosis in galactosaemia: results of a survey of 350 cases. J Inherit Metab Dis 1990;13(6):802-18.

20. Forges T, Monnier-Barbarino P, Faure GC, Bene MC. Premature ovarian failure in galactosaemia: pathophysiology and clinical management. Pathol Biol (Paris) 2003;51:47-56.

21. Betterle C, Dal Pra C, Mantero F, Zanchetta R. Autoimmune adrenal insufficiency and autoimmune polyendocrine syndromes: autoantibodies, autoantigens, and their applicability in diagnosis and disease prediction. Endocr Rev 2002;23(3):327-64.

22. Laml T, Preyer O, Umek W, Hengstschlager M, Hanzal E. Genetic disorders in premature ovarian failure. Hum Reprod Update 2002;8(4):483-91.

23. Matthijs G, Schollen E, Pardon E, Veiga da Cunha M, Jaeken $\mathrm{J}$, Cassiman $\mathrm{J}$, et al. Mutations in PMM2, a phosphomannomutase gene on chromosome 16p13, in carbohydrate deficient glycoprotein type I syndrome (Jaeken syndrome). Nat Genet 1997;16:88-92.
24. Aittomaki $K$, Lucena JL, Pakarinen $P$, Sistonen $P$, Tapanainen $\mathrm{J}$, Gromoll J, et al. Mutation in the follicle-stimulating hormone receptor gene causes hereditary hypergonadotropic ovarian failure. Cell 1995;82(6):959-68.

25. Rousseau-Merck MF, Atger M, Loosfelt $H$, Milgrom E, Berger $\mathrm{R}$. The chromosomal localization of the human follicle-stimulating hormone receptor gene (FSHR) on 2p21-p16 is similar to that of the luteinizing hormone receptor gene. Genomics 1993;15(1):222-4.

26. Aittomaki K, Herva R, Stenman UH, Juntunen K, Ylostalo P, Hovatta $\mathrm{O}$, et al. Clinical features of primary ovarian failure caused by a point mutation in the follicle-stimulating hormone receptor gene. J Clin Endocrinol Metab 1996;81(10):3722-6.

27. Beau I, Touraine P, Meduri G, Gougeon A, Desroches A, Matuchasky $C$, et al. A novel phenotype related to partial loss of function mutations of the follicle stimulating hormone receptor. J Clin Invest 1998;102(7):1352-9.

28. Touraine P, Beau I, Gougeon A, Meduri G, Desroches A, Pichard $C$, et al. New natural inactivating mutations of the follicle-stimulating hormone receptor: correlations between receptor function and phenotype. Mol Endocrinol 1999;13(11):1844-54.

29. Doherty E, Pakarinen P, Tiitinen A, Kiilavuori A, Huhtaniemi I, Forrest $\mathrm{S}$, et al. A Novel mutation in the FSH receptor inhibiting signal transduction and causing primary ovarian failure. J Clin Endocrinol Metab 2002;87(3):1151-5.

30. Allen LA, Achermann JC, Pakarinen P, Kotlar TJ, Huhtaniemi IT, Jameson JL, et al. A novel loss of function mutation in exon 10 of the $\mathrm{FSH}$ receptor gene causing hypergonadotrophic hypogonadism: clinical and molecular characteristics. Hum Reprod 2003:18(2):251-6.

31. Meduri G, Touraine P, Beau I, Lahuna O, Desroches A, Vacher-Lavenu MC, et al. Delayed puberty and primary amenorrhea associated with a novel mutation of the human folliclestimulating hormone receptor: clinical, histological, and molecular studies. J Clin Endocrinol Metab 2003;88(8):3491-8.

32. da Fonte Kohek MB, Batista MC, Russell AJ, Vass K, Giacaglia $L R$, Mendonça BB, et al. No evidence of the inactivating mutation (C566T) in the follicle-stimulation hormone receptor gene in Brazilian women with premature ovarian failure. Fertil Steril 1998:70(3):565-7.

33. Sundblad V, Chiauzzi VA, Escobar ME, Dain L, Charreau EH. Screening of $\mathrm{FSH}$ receptor gene in Argentine women with premature ovarian failure (POF). Mol Cell Endocrinol 2004;222(1/2):53-9.

34. Latronico AC, Anasti J, Amhold IJ, Rapaport R, Mendonça $\mathrm{BB}$, Bloisse W, et al. Brief report: testicular and ovarian resistance to luteinizing hormone caused by inactivating mutations of the luteinizing hormone-receptor gene. N Engl J Med 1996;334(8):507-12.

35. MacNaughton J, Banah M, McCloud P, Hee J, Burger H. Age related changes in follicle stimulating hormone, luteinizing hormone, oestradiol and immunoreactive inhibin in women of reproductive age. Clin Endocrinol (Oxf) 1992;36(4):339-45.

36. Shelling AN, Burton KA, Chand AL, van Ee CC, France JT, Farquhar CM, et al. Inhibin: a candidate gene for premature ovarian failure. Hum Reprod 2000;15(12):2644-9.

37. Conway GS. Clinical manifestations of genetic defects affecting gonadotrophins and their receptors. Clin Endocrinol (Oxf) 1996;45(6):657-63

38. Sedmak DD, Hart WR, Tubbs RR. Autoimmune oophoritis: a histopathologic study of involved ovaries with immunologic characterization of the mononuclear cell infiltrate. Int $\mathbf{J}$ Gynecol Pathol 1987;6(1):73-81.

39. Eisenbarth GS. Autoimmune polyendocrine syndromes. N Engl J Med 2004;350:2068-79.

40. Society of Obstetricians and Gynaecologists of Canada (SOGC) clinical practice guidelines. Uterine fibroid embolization (UFE). Number 150, October 2004. J Gynaecol Obstet 2005;89(3):305-18.

41. Matikainen T, Perez GI, Jurisicova A, Pru JK, Schlezinger JJ, Ryu HY, et al. Aromatic hydrocarbon receptor-driven Bax gene expression is required for premature ovarian failure caused by biohazardous environmental chemicals. Nat Genet $2001 ; 28(4): 355-60$ 
42. Bastos CA, Lisboa KO, Fuchs SC, Donato GB, Spritzer PM. Determinants of ovarian pre- menopausal transition and postmenopausal women: a population based study. Maturitas 2005;53(4):405-12

43. Nelson LM, Anasti JN, Kimzey LM, Defensor RA, Lipetz KJ, White BJ, et al. Development of luteinized graafian follicles in patients with karyotypically normal spontaneous premature ovarian failure. J Clin Endocrinol Metab 1994;79(5):14705.

44. Massin N, Gougeon A, Meduri G, Thibaud E, Laborde K, Matuchansky C, et al. Significance of ovarian histology in the management of patients presenting a premature ovarian failure. Hum Reprod 2004;19(11):2555-60.

45. Henzl MR, Loomba PK. Transdermal delivery of sex steroids for hormone replacement therapy and contraception. A review of principles and practice. J Reprod Med 2003;48(7):525-40.

46. Vilodre LC, Wender MC, Castro JA, Reis FM, Ruschel S, Magalhães $\mathrm{JA}$, et al. Endometrial response to cyclic regimen of percutaneous 17- $\beta$-estradiol and low-dose vaginal micronized progesterone in women with mild to moderate hypertension. Gynecol Endocrinol 2003;17(4):323-8.

47. Jones SC. Subcutaneous estrogen replacement therapy. J Reprod Med 2004;49(3):139-42.

48. Spritzer PM, Mallmann ES, Vilodre LC. Estrogênios, Progestogênios e Androgênios. In: Camargos A (ed). Ginecologia Ambulatorial. $2^{\mathrm{a}}$ ed. Belo Horizonte: Coopmed, 2007 [no prelo].

49. Hartmann BW, Kirchengast S, Albrecht A, Laml T, Soregi G, Huber JC. Androgen serum levels in women with premature ovarian failure compared to fertile and menopausal controls. Gynecol Obstet Invest 1997;44:127-31.
50. Bachelot A, Meduri G, Massin N, Misrahi M, Kuttenn F, Touraine P. Ovarian steroidogenesis and serum androgen levels in patients with premature ovarian failure. J Clin Endocrinol Metab 2005;90(4):2391-6.

51. Check JH, Chase JS, Spence, M. Pregnancy in premature ovarian failure after therapy with oral contraceptives despite resistance to previous human menopausal gonadotropin therapy. Am J Obstet Gynecol 1989;160(1):114-5.

52. Paulson RJ, Hatch IE Lobo RA, Sauer MV Cumulative conception and live birth rates after oocyte donation: implications regarding endometrial receptivity. Hum Reprod $1997 ; 12(4): 835-9$

53. Donnez J, Dolmans MM, Demylle D, Jadoul P, Pirard C, Squifflet $J$, et al. Livebirth after orthotopic transplantation of cryopreserved ovarian tissue. Lancet 2004;364(9443):1405-10.

54. Eastell R. Management of osteoporosis due to ovarian failure. Med Pediatr Oncol 2003;41(3):222-7.

55. Kalantaridou SN, Naka KK, Bechlioulis A, Makrigiannakis A, Michalis L, Chrousos GP. Premature ovarian failure, endothelial dysfunction and estrogen-progestogen replacement. Trends Endocrinol Metab 2006;17(3):101-9.

\section{Endereço para correspondência:}

Poli Mara Spritzer

Serviço de Endocrinologia

Hospital de Clínicas de Porto Alegre

Rua Ramiro Barcelos 2350

90050-170 Porto Alegre, RS

Fax: (51) 3316-3656

E-mail: spritzer@ufrgs.br 